\title{
Seeing Beyond the Eating Disorder: The Complexities of Eating Disorder Care in New Brunswick, Canada
}

\author{
Tanya Wilson ${ }^{1}$ and Kathryn Weaver ${ }^{2}$ \\ ${ }^{1}$ Senior Health Consultant, Government of New Brunswick, Canada \\ ${ }^{2}$ Professor, Faculty of Nursing, University of New Brunswick, Canada \\ ${ }^{1}$ tanya.wilson@gnb.ca, ${ }^{2}$ kweaver@unb.ca
}

\begin{abstract}
Health professionals struggle in caring for individuals with eating disorders, especially in New Brunswick, Canada where there is no recognized eating disorder treatment center. Using a narrative approach, this study explored the perceptions and experiences of professionals from seven regulated health professions that are most commonly involved in eating disorder care - medicine, dentistry, nursing, social work, occupational therapy, dietetics, and psychology. The findings bring to light the complexities of eating disorder care and the process that professionals go through in seeing beyond the eating disorder to understanding the often subtle subtexts that impede eating disorder identification and treatment. Looking at eating disorder care from an interprofessional perspective provides unique insight into the common needs and challenges of practitioners and may ultimately inform treatment and prevention initiatives.
\end{abstract}

Keywords: Eating disorder, Health professional, Narrative analysis, Interdisciplinary perspective

\section{Introduction}

Eating disorders, the most life-threatening of all psychiatric illnesses [1], require prompt identification and specialized treatment. Although eating disorders - anorexia nervosa, bulimia nervosa, binge eating disorder, and other specified feeding and eating disorders - each has a specific set of criteria used in diagnosis and treatment, all are characterized by maladaptive eating patterns and behaviors. The Diagnostic and Statistical Manual of Mental Disorders 5th Edition defines eating disorders as "persistent disturbance[s] of eating or eating-related behavior resulting in altered consumption or absorption of food, significantly impairing physical health or psychosocial functioning" [2]. Although eating disorders can affect all genders, prevalence is higher among those who identify as girls and women [3][4]. Eating disorders typically present in adolescence, and to a lesser degree, in pre-pubertal children [5] and older adults [6]. The prevalence of anorexia nervosa among women and girls is $0.3-1 \%$, while bulimia has a prevalence of between $1-3 \%$ in females [7]. Anorexia nervosa is the third most common chronic condition in adolescence [8][9]. Research suggests that only half of all individuals affected by anorexia nervosa and one-third of those experiencing

Article history:

Received (June 27, 2019), Review Result (July 24, 2019), Accepted (October 29, 2019) 
bulimia nervosa are ever detected by the healthcare system [9]. Furthermore, there is a gap in knowledge of best practices for managing eating disorders in communities [4]. Thus, health professionals may struggle to identify and care for affected individuals in New Brunswick, Canada where there is no recognized eating disorder treatment center or a clear pathway to care.

\section{Literature review}

We used the search terms "health professional*" OR "doctor" OR "dentist" OR "nurse" OR "occupational therapist" OR "social work*" OR "psychologist" OR "dietitian" AND "perceive" OR "perspective" OR "attitude" OR "understanding" OR "knowledge" OR "practice" OR "skill” AND "eating disorder*" OR "anorexia" OR "bulimia" OR "binge eating." We searched PsychInfo, CINAHL, Sociological Abstracts, and PubMed databases. Applying limiters of peer-review, English language, and 2009-2019 as well as manual searching of bibliographies and removing duplicates, 168 articles were located. Articles that did not mention the perspectives of health professionals in the abstracts were excluded for a total of 34 articles reviewed. This literature conveyed perceptions, knowledge, skill, and attitudes in providing care or services to individuals and families affected by eating disorders. The perspectives of dentists and hygienists, occupational therapists, nurses, dietitians, social workers, physicians, and psychologists are discussed separately and together.

\subsection{Health professionals' unique roles}

The roles of each professional are based on disciplinary knowledge and training. In general, the more training, the greater the comfort in detecting and initiating treatment or referrals for persons struggling with eating disorders.

\subsubsection{Dentists and hygienists}

Oral-dental problems present as early as six months from the onset [10], with symptoms depending on the type of eating disorder. Dental erosion, caries, enamel loss, and tooth sensitivity may be noted [5][10]. Dentists and hygienists with proper training are key to the early detection of eating disorders and secondary prevention of illness [11]. DeBate et al. [12] found that many oral health professionals screen for eating disorders but do not provide specific care or refer patients with suspected eating disorders. Increased self-efficacy, knowledge of eating disorders, and recognition of these illnesses as significant health threats increase the likelihood of secondary prevention practices [12].

\subsubsection{Occupational therapists}

Working collaboratively with other health professionals, occupational therapists focus on assisting with school, work, social function, leisure engagement, and building identity and support outside of the eating disorder [13]. When patients are adolescents, occupational therapists involve the families as appropriate to accomplish goals of success in school, extracurricular activities, employment, and re-engagement in meaningful activities. Teaching time management, meal planning, and preparation, household and budgeting management, and healthy coping skills assist affected persons to manage eating disorders in social situations that involve food, self-care, and independent living [14]. Factors relating to successful intervention include a longer duration of in-patient treatment and high collaboration between team members [13]. 


\subsubsection{Nurses}

The life-or-death nature of eating disorders, particularly anorexia nervosa, challenges the development of therapeutic rapport, as patient survival often overrides the option to slowly develop therapeutic alliances [15]. Due to their continual presence in hospital units, nurses develop caring, empathetic, and trusting relationships in line with the person-centered approach to care [8]. These nurses assist patients to adhere to treatment while facing deep, painful, traumatic thoughts and emotions [16]. In turn, patients were found to view pressure to eat from the treatment team as pivotal in breaking restrictive eating patterns [17]. Nurses stress the importance of gradually transferring responsibility back to the individual and developing a relapse plan as vital to recovery [17]. Beyond bedside nursing, nurse practitioners (NPs) may apply cognitive behavioral therapy principles and conduct medical histories, medication reviews, lab reviews, reviews of systems and physical assessment, and medical monitoring while patients are in treatment; NPs further collaborate with the team regarding the appropriateness of treatment in outpatient care settings [18].

\subsubsection{Dieticians}

Endorsing a collaborative interdisciplinary treatment approach to intervention [19][20], dieticians emphasize the importance of a strong patient-professional alliance [21] and wellestablished protocols for nutrition management [19]. A slow approach to prevent the refeeding syndrome, a potentially life-threatening complication related to nutrient deficiencies [9], is required, especially in the initial 7-10 days of nutritional treatment [21]. Tube feeding practices are considered a last resort, with other approaches regarded as more favorable for weight restoration [21]. There is a need for ongoing research to establish norms for disordered patterns of eating and best dietary practice. Without such guidelines, professionals rely on clinical judgment [21] and personal experience [20] to recognize maladaptive eating patterns before they become medical crises.

\subsubsection{Social workers}

Family therapy is a proven best practice in eating disorder care with youth and adolescents [22]. Many family therapists have social work as their disciplinary background [23]. Social work students have reported that eating disorders are viewed as shameful or embarrassing, and are not taken as serious mental illnesses [24]. To overcome this limited knowledge and awareness about eating disorders, social workers prepare youth and families for healthy weight transition, nurture parents for supportive roles beyond weight restoration, and advocate for needed resources and policies within the eating disorder community. The social work onus is on helping young adult patients learn to successfully manage their recovery needs and life transitions. Community-based social workers who completed four intensive didactic training sessions designed to improve knowledge and assessment of eating disorders showed significant improvement [25]. The study also found that with training, social workers were more likely to screen new patients. However, training did not influence the perceived ability to intervene.

\subsubsection{Physicians}

Primary care, in general, and the role of physicians specifically, are crucial to the early identification and treatment of eating disorders [26][27][28]. There is a strong correlation between eating disorder training and comfort level in identifying and managing eating 
disorders [29][30]. Increased knowledge and screening results in early detection and intervention by physicians [27][31][32]. Yet, medical providers may still lack the training and confidence to intervene. To illustrate, McNicholas et al. [27] discovered that only $14.9 \%$ of physician respondents felt confident in their ability to manage eating disorders. Similarly, Linville et al. [32] found $78 \%$ of medical providers were unsure of how to treat eating disorders, 92\% felt they missed a diagnosis, and 67\% reported a need for continuing education. Even among psychiatrists, there remained a need for improved education related to diagnosis and treatment [33]. This may relate to the finding that psychiatrists were pessimistic about prognosis [28]. Misconceptions that eating disorders are self-inflicted and within a person's control [28] and that persons with anorexia nervosa typically look underweight [34] further delay identification and treatment.

\subsubsection{Psychologists}

In a Canadian study, physicians' and psychologists' self-assessed competence, barriers, and needs were examined in treating children and youth living with eating disorders [32]. Findings showed that more than $90 \%$ of the health professionals had encountered patients whom they were unable to treat due to limited skill, case complexity, and lack of resources. Psychologists whose practice did not involve treatment for eating disorders reported low selfassessed competency related to the diagnosis and treatment of eating disorders [32]. Psychologists who showed high self-assessment (which was hypothesized to be related to specialized training) were challenged more by case complexity than skill development, and this led researchers to conclude that all clinicians at some point struggle with some cases [32]. These findings point to a need for better training and suggest that practice barriers rather than logistical factors impede the ability to intervene. Such barriers result from system factors (e.g., payment restrictions), attitudinal factors (e.g., providers who believe that eating disorders are uncommon in an ethnic minority group may fail to detect an eating disorder in a client from the minority group), or both [37]. Best practice has been established as psychotherapy for persons who restrict and as cognitive behavioral therapy alone or with antidepressants for binge eating and purging behaviors [34][35][36][37].

\subsubsection{Challenges to providing care and services from an individual profession}

Patients do not typically present with a primary complaint of an eating disorder [5]. Often, they try to disguise their appearance to avoid detection and seek help for related issues such as anxiety rather than disclose the eating issue [38]. As well, professionals cannot rely on physical presentation as individuals affected by bulimia nervosa, for example, may present with normal weight and without peripheral school- or work-related issues [5]. Other challenges include high relapse and patients' attempts at 'fooling the system' [13]. Moreover, the perception that eating disorder intervention requires specialist skills forms a barrier to providing care and services [39][40]. Persistent stigma, characteristic secrecy, the insularity of working in individual professional hierarchies rather than interprofessional teams, anticipating defensiveness from patients, and time constraints impede the uptake of universal screening of eating disorders [9][29][31][33].

\subsection{Interprofessional approach to care}

According to the World Health Organization, interprofessional care occurs when multiple health providers from different professional backgrounds work together with patients, 
families, and communities to deliver high-quality care [41]. This collaboration contributes to positive patient outcomes particularly in mental health [42]. An interprofessional approach is needed to address the psychological, medical, interpersonal, and sociocultural features that define and perpetuate the eating disorder [43][44] because no single profession is prepared to meet the complex patient needs [11][18][31][45][46]. Incorporating an interprofessional approach enables intervention that targets psychiatric, medical, psychological, and sociocultural influences of eating disorders as well as beliefs and behaviors associated with body shape, size, weight, food, eating, and exercise. To this end, specialists in each area collaborate to help patients work toward recovery.

\subsubsection{Challenges to the interprofessional approach}

Professional judgments made in the context of interprofessional teams are influenced by the inherent and potentially competing values of the respective professions [40]. Such values can reduce trust and cooperation which are recognized as paramount to optimal care for persons affected by eating disorders [13].

\subsubsection{Family as team members}

Families are not always involved in treatment planning [47]. Parents have been perceived as a challenge to treatment [48]. Even when families are recognized as a positive resource for information as they know their child best, flawed empirical research (e.g., diversity of data collection instruments and lack of comparison groups) has contributed to negative perceptions of the characteristics of families living with anorexia nervosa and bulimia nervosa [49]. Current research suggests that outpatient family-based therapy is considered the best practice for adolescents with eating disorders [5][50][51]. However, the transition from pediatric to adult programs is difficult for families accustomed to being involved in the circle of care [52].

\subsection{Summary of literature reviewed}

Despite knowledge of the particularities of eating disorders, research conveys eating disorders as complex psychiatric illnesses that are difficult to recognize and require specialized care from trained health professionals. Although interprofessional collaboration is paramount, competing values and fragmented care impede professional partnerships. Families can play a critical role in intervention and treatment but may remain outside the care circle. The need for integrated health care is extolled; yet, most research reflects the viewpoint of individual professions. According to the available evidence, formal education and training needs are not addressed. Thus, we focussed on understanding professionals' knowledge, skills, and experiences in the context of providing eating disorder care and services to individuals, families, and communities.

\section{Study purpose}

We sought to elicit the experiences of health professionals through three exploratory qualitative questions: 1) What are the stories of health professionals who provide services to persons affected by eating disorders? 2) How do health professionals conceptualize eating disorders, recovery, and provision of health services? and 3) What are the knowledge and practice needs of health professionals regarding eating disorder intervention and recovery? To answer these questions, we invited New Brunswick health providers from seven regulated health professions (medicine, dentistry, nursing, occupational therapy, psychology, social 
work, and dietetics) to reflect on their perceptions and training and to share their experiences in providing treatment and intervention.

New Brunswick is one of four Atlantic Provinces situated on the east coast of Canada. With a population of approximately 750,000 inhabitants [53][54], small cities and rural communities are characteristic. New Brunswick lacks a provincially recognized eating disorder treatment center. Although pockets of expertise exist, approaches to eating disorder care are fragmented.

\section{Design and method}

We used a narrative, constructivist approach[55] to research design. Constructivism is based on the idea that knowledge is constructed by the knower; thus, participants' understanding would be formed via reflection on their personal experiences and relating new knowledge to the knowledge they already possessed [56]. Due to its exploratory style, our narrative constructivist approach proved a non-threatening method to elicit the stories of physicians, nurses, social workers, and others who care for individuals affected by eating disorders. This method facilitated a natural flow of dialogue, facilitating an authentic account of participants' experiences in eating disorder care.

\subsection{Narrative, constructivist approach}

The narrative inquiry examines how people understand and interpret their lived experiences through telling, re-telling, and re-living their stories [57]. Narrative inquiry is "an amalgam of interdisciplinary analytic lenses, diverse disciplinary approaches, and both traditional and innovative methods - all revolving around an interest in biographical particulars as narrated by the one who lives them" [58][59]. We sought to represent the stories of participants as they were lived and told.

\subsection{Sample}

A purposive sample was recruited via provincial online classified advertisements, handdelivered posters to health professionals and health conferences, professional listservs, and snowball technique. Participants were required to be English-speaking, professionally trained, registered with a provincial regulatory body, and have professional experience providing care and services to people affected by eating disorders. Eight licensed professionals representing seven regulated health disciplines (medicine, dentistry, nursing, social work, occupational therapy, dietetics, and psychology) took part. Participants represented a range of settings from primary care, acute care, outpatient services, and private practice with adult and pediatric populations. Most had practiced in their respective health discipline for over ten years. All but one participant was female.

\subsection{Data collection}

Using narrative principles, and adhering to institutional ethics policy, data collection involved engaging participants in sharing their experiences as health professionals providing eating disorder care. Data were collected over four months via in-depth audio-recorded, semistructured interviews each lasting 30-50 minutes. Except for one telephone interview, all were conducted face-to-face in the location of the participant's choice.

\subsection{Data analysis}


Interview data were transcribed verbatim and anonymized. Preliminary analysis entailed listening and re-listening to the recordings. Analysis created core stories unique to each participant's experience. A core story is a concentrated representation of a participant interview with repetition and extraneous content removed [53]. Working within and across the individual core stories, patterns both unique and common to participants were identified in an aggregated collective core story.

\subsection{Rigor and validation with participants}

We maintained the accuracy and credibility of results through peer debriefing, reflexive journaling, and safeguarding participant rights. Informally, member checking occurred during data collection by clarifying points made in the research interviews. Following analysis, core stories were provided to those who consented to see them. The response was limited to one participant; however, this feedback indicated an accurate representation of health professionals' struggles.

\section{Findings}

[Figure 1] shows the complexity of care is complicated by the many facets of eating disorders and the patchwork of healthcare system services. From the data, two distinct themes emerged within the social context: 1) the nature of eating disorders and 2) the valuing of health priorities. Bridging these intersecting themes is the process of seeing beyond the eating disorder with its threads of tension, anticipating care needs, taking stock, mobilizing resources, affectivity, and overcoming resistance.

\subsection{Social context}

Health professionals cannot escape the predominant social and cultural influences that affect opinions, beliefs, and ultimately professional practice. According to Participant 8:

Initially, I would fall into the same category as the public, thinking that eating disorders were simply a cry for attention. Learning about the condition has changed my perception, including society's role in creating the ideal body image and looking differently at the multimillion-dollar diet industry.

Highlighting the challenge of sifting through available nutritional information, Participant 7 said, "There is a lot of news around gluten, starch, and portions. People think this is the truth. Even I question myself and I know better. How much more is it going to affect someone who doesn't know?"

\subsection{Nature of eating disorders}

The many facets of eating disorders complicate identification, early intervention, and treatment. Professionals attune to both what is being said and what is not readily disclosed. Narrative threads of secrecy, severity, ticking time bomb, toll and devastation, and openness to help-seeking emerged.

\subsubsection{Secrecy}

The secret nature of the eating disorder initially obscures professionals' ability to identify the illness. Eating disorders can present as a pre-occupation, for example, "clients who want to be 100 pounds because it is a nice round number" (Participant 7), or as a restriction: 
Right away she questioned how much food she has to take [her prescribed medication]. I questioned if it was a problem for her to take it with food because we just talked about disordered eating. Not wanting to take medication because she has to take it with food was a screaming red flag (Participant 4).

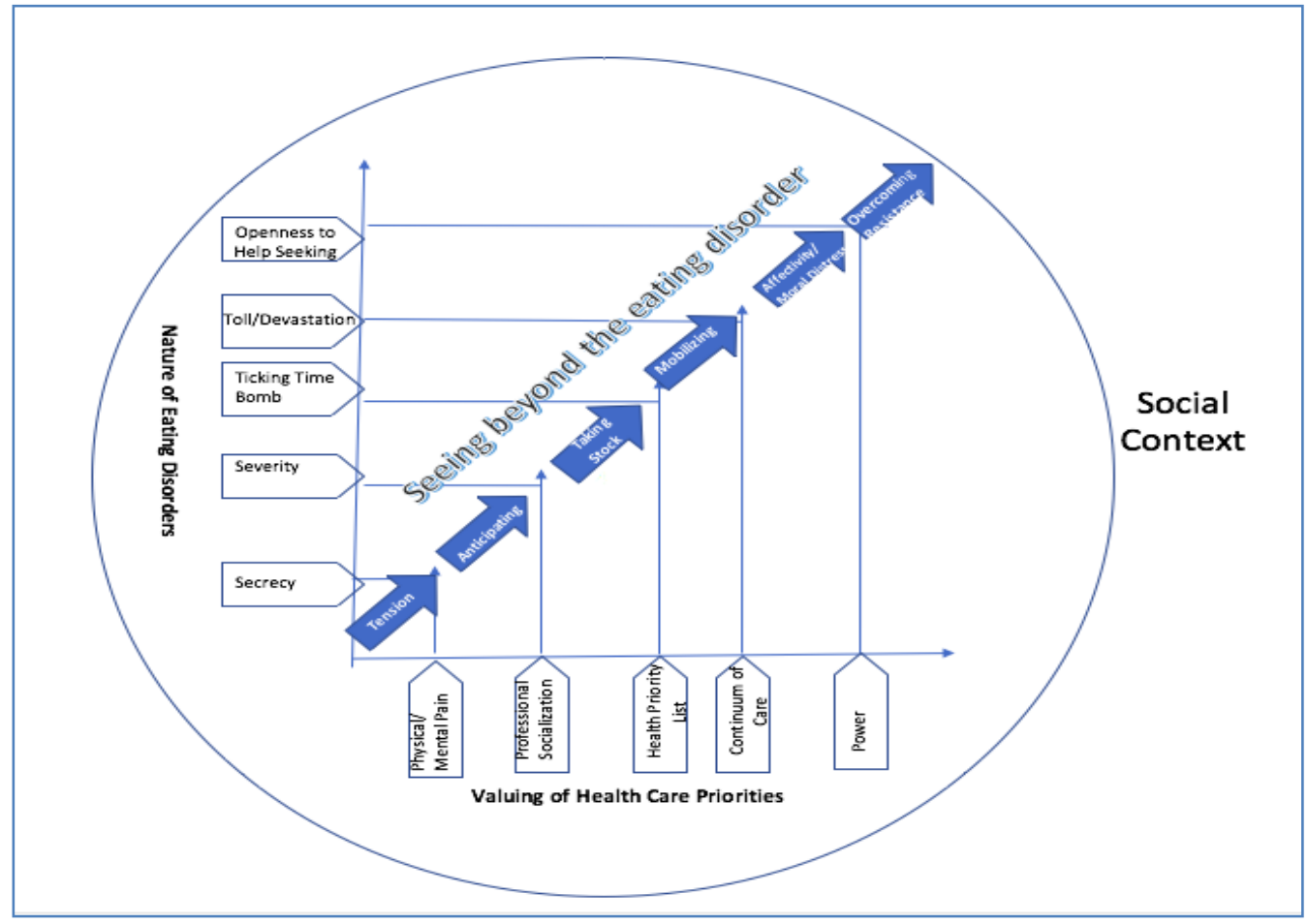

Figure 1. The complexity of eating disorder care

The affected person may be emaciated or malnourished without the eating disorder identified, as in the case of "some morbidly obese clients [whose] idea about losing weight is not eating or eating one meal a day. They will never get to the point where they would be emaciated but it can still affect their health" (Participant 7). Professionals have difficulty identifying the eating disorder when their patients have "a hard time naming it" (Participant 4) or "it's not something the patient wants to talk about" (Participant 5). As in previous research [37], the focus of help-seeking is on co-morbid conditions. "Denial as a primary response" (Participant 1) complicates early discernment. Indeed, "the sicker patients are the ones who are better at keeping it under wraps" (Participant 5).

\subsubsection{Severity}

As the illness advances, symptoms become more visible, more severe, and harder to ignore. The progression of the disorder is described as "debilitating" when "some [patients] are starved to the point of experiencing scary symptoms" (Participant 2). Patients become socially withdrawn and struggle to remain active in school, work, and leisure pursuits. Participant 5 talked about a patient who "quickly got very sick and had to stop every activity. She was not socializing or going anywhere, couldn't work, and had to leave university." Patient functioning becomes profoundly affected. "Sometimes they couldn't even walk to the bathroom. They needed a wheelchair" (Participant 3). Anorexia nervosa can be particularly 
challenging, as "their mortality rate is highest," yet may be overlooked initially. "I have had doctors admit that a patient is pretty thin but it is just dismissed. And I think "wow, we need to address this now!'” (Participant 2).

\subsubsection{Ticking time bomb}

Early detection can allow for a more preventative role and may avoid hospitalization or additional complications. "If I catch it early enough then it's not anything I would treat. In these instances, my role is more preventative, trying to educate patients" (Participant 1). Likened to a "ticking time bomb" (Participant 2), the need to treat the disorder is timesensitive. "If pediatricians or family doctors can make a referral as soon as there are warning signs, I find that works better" (Participant 6). When the illness progresses, therapy is challenged by the social, emotional, and physical effects. If left unaddressed, "behaviors are so entrenched and families so depleted that it makes it difficult to do outpatient therapy" (Participant 2). Professionals sense "their [patients'] lives are in your hands" (Participant 3). Thus, "if left untreated, they can die or continue to have issues into adulthood" (Participant 6).

\subsubsection{Toll and devastation}

Pain and suffering are not limited to the affected person but extend to the entire family unit, permeating all aspects of their lives. "Every family's worst fear is the most severe outcome, which is death" (Participant 5). Parents, whose lives are in turmoil, are "so burnt out" and "so tired" (Participant 3) that they need their support. "As soon as you start the [intervention], everything comes out and the whole [family] system is shaken up and under tremendous stress" (Participant 6). The toll includes emotional stress as well as the "financial cost to leave work, put gas in the vehicle, and leave other children at home and make arrangements for their [unaffected child's] care" (Participant 8). Parental self-blame and exasperation are intense.

As parents, your instinct is to feed your child, take care of, and nurture your child. When parents can't do that, it's actual torture and suffering for the parent. There wasn't a single parent that didn't say 'why didn't I notice' or 'do something sooner' or didn't blame himself or herself and ask why they were not able to feed their child. (Participant 3)

\subsubsection{Openness to helping to seek}

The therapeutic process can be difficult given that food is life-sustaining and cannot be avoided. "Calories tend to be what people are most afraid of as they think they [calories] are going to exercise or body fat" when in fact, calories are necessary "to keep our heart pumping and our kidney filtering" (Participant 7). Beginning the process of recovery, affected people can become "resistant," "oppositional," and "angry" in response to imposed dietary and activity measures (Participant 2) and attempts to "change [their] self-perception" (Participant 4). Although "eating disorders are not about food," food becomes "that piece that they can control" when the eating disorder "results [ed] from a trauma" outside the patient's control (Participant 6). It is challenging to gain "patient buy-in and ability or willingness to participate to get to a better place" (Participant 4). Compensatory behaviors (e.g., restricting, purging) persist even with knowledge and treatment. "They know about good nutrition and what they should be eating. It's about getting them to make small steps or to find that one food that scares them and incorporate that in their day" (Participant 7). Participants explain to 
patients and families "it's a long road to recovery and there are still going to be bumps along the way" (Participant 8).

\subsection{Valuing of health priorities}

The second overarching theme relates to the valuing of health priorities within the healthcare setting. This theme is captured within threads of physical and mental pain, professional socialization, health priority lists, continuum of care, and power.

\subsubsection{Physical and mental pain}

The quality of mental health care has historically lagged behind that of physical care. Physical complications, for example, epigastric pain and cardiac issues, are more readily recognized and responded to than less overt mental health symptoms, like emotional distress and perceived self-harm. To illustrate, Participant1 described a patient "being treated for gastric reflux, but it's not just gastric reflux. She is malnourished and underweight - it's anorexia." Professionals attempting to facilitate access to eating disorder care struggle to find resources until the need reaches an alarming level, leaving both professionals and those in their care vulnerable, "There are no resources. I've sent people to the hospital in the past and it doesn't work. Unless they are medically unstable, they are not going to get a bed" (Participant 6).

\subsubsection{Professional socialization}

Professionals experience inadequate formal training and ongoing professional development with eating disorders. As Participant 1 stated, "we were taught some information, but it was a quick run-through." Limited knowledge contributes to missed diagnoses or sub-optimal care.

I have been in practice for 20 years. I am sure that at that period [early career], I missed a lot because the question didn't come up and I didn't ask. Knowing what I know now, I have seen an extraordinary number of eating disorders. (Participant 5)

The development of professional attitudes, skills, knowledge, and beliefs acquired through training and experience has a profound effect on patient care. "People [professionals] always mean well but even one small, misinformed comment can cause harm" (Participant 8).

To address gaps in learning, participants have to "learn by myself along the way" (Participant 3), "do my research" (Participant 8), and "self-teach" (Participant 5). Some consult specialists in other Canadian provinces (Participants 3,5). Even with experience, providing eating disorder care can feel like "treading water" (Participant 6).

\subsubsection{Health priority list}

Frequently characterized by under-served and underfunded programs, mental health care in general, and eating disorders specifically, have not been prioritized under current health services. "Some patients can wait 6 months for service at mental health [services]. With an eating disorder, this is too long to wait" (Participant 6). Lack of public coverage for private treatment is another issue because "if patients don't have private coverage, they have to pay out of pocket" (Participant 7). For out-of-pocket costs, Participant 6 stated, "If they can only come to see me [in private practice] once every 4 to 6 weeks because their parents can't afford more than that, it's not that helpful and they don't get much better." Moreover, the requirement for out-of-province care can be complicated as "I know colleagues who have 
[referred to out-of-province treatment] and out-of-province billing is another matter" (Participant 4).

\subsubsection{Continuum of care}

Closely following health priority lists are issues related to the health system's continuum of care. System responsiveness is guided by symptoms, both in the community and in the hospital with "fragmentation of care mak[ing] things difficult" (Participant 4) and "trying to find the consistency among team members a challenge" (Participant 3). As Participant 2 put it, "we know what the health system is like. Once someone is medically stable, they are going to go home but are still very ill." This participant pointed out the consequence of early discharge from the hospital as "parents end[ing] up providing hospital care at home." Only when pushed, does the system seem to respond, and then only for the time it takes to stabilize a person and return them to the community. "Patients were discharged when they shouldn't have as there continued to be issued playing into the eating disorder behaviors" (Participant 8). Consequently, professionals are left to create and implement a plan of care from the existing patchwork of services, "just doing the best that we could" (Participant 2). There is a need to provide a "team" approach (Participants 2,8). Reflecting on the myriad of service providers involved with the care of just one patient, Participant 4 found it "very, very difficult to try to reel everything in, to get a full continuity of care, and to get a full sense of what is happening." To improve care and services to patients, professionals want a coordinated clinic or program (Participant 8) rather than "working in separate silos" (Participant 4).

\subsubsection{Power}

At every level, power dynamics play out - from what gets funded and why, to valuing physical over perceived self-harm symptoms, to professional development opportunities, and lastly, to the lack of dedicated inpatient and community resources for eating disorder care. "What stands out is who is supposed to be working on this file. There ends up being this divide between medical practitioners and hospital and community mental health" (Participant 2). Professionals who are "not involved with other professionals in the treatment of the patient ... need consent to communicate." Participant 1 continued with "Doctors aren't good at sharing. It's their protected turf. But it's not their 'turf.' It's the patients. Sometimes parents will report that she is getting counseling and help. And other times I don't know what the physician does."

There is difficulty engaging specific professional groups. For instance, "we [team] may think that a patient needs to be seen but psychiatrists will just say no" (Participant 7). Health professionals may be restrained by regulatory limits imposed on them; for example, "nurse practitioners can order diagnostic tests and refer to specialists, but don't have hospital privileges" (Participant 4). Limits are also imposed on patient status, as illustrated by the requirement for patients "to be physically stable, have a certain BMI, and full medical clearance" (Participant 2) to be accepted into out-of-province facilities. Reflecting on the time required to get the patient approved for treatment, Participant 2 surmised that "if she had spent all those months in treatment for her anorexia that would have been beneficial - that's a pretty huge gap in our system." Professionally who gets recognized; who gets intimidated, silenced, or ignored; who is granted admitting privileges; who gets invited into the circle of care and under what circumstances; and which disciplines get called to the decision-making table are all examples of power dynamics at play in health care. "The medical community does not seem to be able to come together and advocate for patients" (Participant 5). 


\subsection{Seeing beyond the eating disorder}

Within the context of a multi-faceted eating disorder and working within the framework of an under-resourced healthcare system, health professionals, often in isolation, must determine appropriate action. Seeing beyond the eating disorder is a graduated process characterized by tension, anticipating care needs, taking stock, and mobilizing resources. It is driven by affectivity, and at times moral distress, and culminates in a point of overcoming resistance.

\subsubsection{Tension}

The transformative process of seeing beyond the eating disorder begins with a sense of tension on the part of the professional who is feeling vulnerable and uncertain. The tension emerges at the intersection of secrecy and physical and mental pain [Figure 1]. "I get patients who are very complex, and I am thinking, 'What am I going to be able to offer this person?"” (Participant 4). Tension also follows "if the team doesn't know the path we're going on and why we're doing it ... Nurses would sometimes disagree about how to do things, and this would affect the patient directly" (Participant 3). To recognize and respond to the physical and mental pain of their patients, health professionals rely on critical thinking, professional skill, and compassion.

Like any profession, it's about learning how to problem solve, how to listen, and how to communicate. If the patient is sick, when is this situation urgent? What does the patient need? (Participant 5)

\subsubsection{Anticipating}

The tension gives way to professionals anticipating the need for a plan of care. They sense the illness is progressing and become aware that symptoms will not resolve on their own. The professionals consider what resources are available, knowing that symptoms of the illness may not receive priority within the health system. "I give them [patients] what I've got in terms of resources and training" (Participant 4). Recognizing the limitations of the situation, professionals give thought to when and how to get their patients into the 'system.' At a certain point, professionals realize that they will need additional resources and support. "You are problem-solving and then you reach a wall when you've sort of done everything you can, but you need some help" (Participant 4).

\subsubsection{Taking stock}

Health professionals take stock of existing resources to mobilize action for their patients. The professional's sense of isolation is strongest while contemplating: "Where do I go? Who do I call?" This can be challenging when there is no established care pathway or available specialized program. As Participant 4 stated, "We need a go-to list of resources that would take some time away from having to do the research ourselves about what is out there and where we can refer." Otherwise, as Participant 7 put it, "I am calling around to know who specializes in eating disorders." Feelings of existing separately from the healthcare system are distressing for professionals as they realize that the system has more gaps than connections in eating disorder care.

It was extremely time-consuming trying to advocate for the patient and her family. It was really difficult because it was hard to find help. As the patient's illness progressed, the resources were really lacking. It was hard to have any justification for the lack of resources for the patient herself but also for the patient's family, whom I was really involved with. You 
are talking about a young person who is an adult, but just seventeen. You know, like anybody's daughter. (Participant 5)

\subsubsection{Mobilizing}

Professionals begin mobilizing resources all the while attesting to the toll the illness is taking on individuals and families. It is difficult to mobilize in silos as "I don't have a role with other health professionals because usually when I get involved treatment has already begun" (Participant 1). However, the mental and physical pain expressed by patients becomes a springboard for professional action. While professionals endeavor to work out a treatment plan, "getting a team together can be difficult" (Participant 7) as power dynamics impede progress. They must deal with who has admitting privileges, who is on the team, and who refuses responsibility for the treatment. Such power dynamics can leave professionals feeling powerless as they search for ways to break the resistance to care. They take whatever action is necessary to ensure that their patient receives care.

This physician was calling all over trying to find where this patient could go. So physically, people were saying they can't take her or don't want her, while mentally, they were saying, 'no, you need to do this.' Somebody has to do something! We can't lose people between the cracks. This physician did not stop until she found somewhere for the patient to go. (Participant 4)

\subsubsection{Affectivity}

Professionals describe affectivity in the context of a memorable story or event that plagues them. The intensity of caring for someone with an eating disorder is "exhausting," "heavy," and "very draining." They adopt strategies to cope with their emotional vulnerability.

I've learned to draw a line in the sand. Unless a team is put in place and we are all working together, I just can't ethically go there. All the players need to be lined up. I've said to parents that I will provide a service but that they need a doctor who will admit the child. Not that admission is a great thing but sometimes patients need to be in the hospital. I think this psychiatrist had no idea how hard it was going to be to get the patient to the hospital and her mother didn't know that this is a really high-risk situation. I only know because I've been through it with families. And it's heartbreak. [Participant 2]

Affectivity enhances the professional's capacity to empathize with those whose lives are touched by the eating disorder. However, professional affectivity is misinterpreted by others as being over-sensitive or overly attached. Such labeling attacks the professional's dignity and can reduce efforts to support the patient. As they bear witness to families receiving inadequate support or paying out of pocket for necessary medical treatment that for other medical conditions would be publicly insured, feelings of injustice erupt. "It's terrible that families and parents have to pay all this money. If they can't access it through a provincial program, then it should be covered through Medicare if they have to go privately" (Participant $6)$.

When affectivity is met with external resistance, moral distress, and moral outrage can develop.

I'm watching the whole family and I'm thinking, it's really unfair because if it were some doctor's daughter in this community, the patient might have better financial resources to just go somewhere else - but no one I know would watch their daughter go through that and accept the care we had. Nobody would. And the response was that I was caring too much! (Participant 5) 


\subsubsection{Overcoming resistance}

Recognition of the imbalance of power and the ensuing moral distress drives professionals to act. Overcoming resistance is a function of the affectivity, moral distress, and outrage that arise from seeing beyond the eating disorder to the individuals and families buckling from the toll of the illness and the limited systemic response. As Participant 6 stated, "It's very frustrating to provide care in this province! We know from research that the shorter period that they have been sick, the quicker the rehabilitation will be and the better the prognosis."

Through the stories of New Brunswick health professionals, the social injustice that stems from the failure of the health system to provide necessary care for an entire group of disorders and the effect on the lives of those affected becomes clear. It is this trigger that prompts individual professionals to share their experiences in the hope that social policy will begin to address the inequity.

How do we have a community where we've just accepted that we don't deal with it? Why are eating disorders different than any other medical issues in front of us? Why is it okay not to have a plan? Why is it okay that we have that in every other area but we accept that we're just going to let these people with eating disorders float around and some are going to spend money in private clinics so they won't be our responsibility? (Participant 5)

\section{Discussion and implications}

Eating disorders are complex, potentially life-threatening illnesses. For health professionals, the puzzling nature and prevailing secrecy challenge recognition and early intervention. Consistent with other research [9][38], this study's findings support the view that secrecy, complexity, and stigma play a role in limiting early detection and treatment of eating disorders. Seeing beyond the eating disorder tasks professionals to look beyond the obvious by considering the unspoken subtexts and conditions that impede identification and action. This process of seeing beyond requires deep professional reflection into the characteristics of eating disorders, the social and cultural conditions that contribute to eating disorder development, and the systemic conditions that influence care.

Professional socialization has the potential to hinder the ability to respond and intervene in eating disorder care. As with other findings [28][45], eating disorder training and professional development was a frequently cited gap. Given the lethality of failing to treat, basic provider knowledge related to eating disorder detection, treatment options, and resources is critical.

This study makes visible the effect of power dynamics in eating disorder care on individuals, families, and healthcare providers. As most individuals will turn to the care provided by primary health professionals, mental health therapists, and private practitioners, consideration must be given to the care continuum by ensuring these practitioners share in the circle of care. This study's results suggest that current approaches to provincial care are contrary to best practice that emphasizes early interprofessional intervention and to the desires of the health professionals who intervene and treat.

A striking finding is the occurrence of moral distress among health professionals providing eating disorder care. Distinguishable from moral dilemmas that are characterized by not knowing the right thing to do, moral distress involves having an awareness of the right course of action but feeling professionally constrained to act [60]. Distress arises when one course of action is considered morally superior but for reasons beyond individual professional capacity, the ability to pursue that course of action is impeded [61]. Moral distress is brought about by the disconnection between professional responsibility and the power to act; it results from failure to maintain professional standards of care. The occurrence of moral distress for study 
participants reinforces understanding of the frustration and outrage that peak, when the responsibility to act, is stymied by systemic constraints. The outcome of moral distress and outrage identified in this study matches other findings of health professionals' responses to being asked to do too much with too little [60]. Safeguards are needed to support health professionals in their effort to provide eating disorder care while avoiding denouncing such care for its systemic shortcomings. As unresolved moral distress can lead to professional burnout [62], findings have significance for both regulators and researchers.

\section{Limitations and further directions}

These findings represent the experiences of eight different health professionals who had experience working in eating disorder care in New Brunswick, Canada. Although this research sample reflected all health professionals who are typically involved in eating disorder care, the sample size was relatively small. However, the sample size was adequate to identify common threads among participants while keeping in mind the study's aim to consider participants as a group rather than to differentiate by professional discipline.

\section{Conclusion}

Inviting health professionals to share their experiences in eating disorder care revealed challenges related to the enigmatic nature of eating disorders and the shortcomings of the health system. Participants' professional experience in eating disorder care enabled them to see beyond the manifestations of the eating disorder itself, to more clearly consider the experiences of individuals and families whose lives are often dominated by the illness, and to contemplate the deficiencies of the system that works against professional efforts to respond. Findings demonstrate a need to ensure that necessary resources are in place to optimize professional intervention. The professionals' narratives must be brought forward to help inform professional education and develop treatment and prevention initiatives. With a trend toward integrated approaches to care within health service delivery, it is essential to fill in the gaps in knowledge of eating disorders and boost the role of integrated care in eating disorder identification and treatment.

\section{Acknowledgments}

This research was funded by an Access Mental Health award to T. Wilson. The project took place within a larger study "Atlantic Canadian Allied Health Professionals in Eating Disorder Care" which received a research grant from the Atlantic Region of the Canadian Association of Schools of Nursing to K. Weaver. The authors declare that there is no conflict of interest.

\section{References}

[1] J. Arcelus, A.J. Mitchell, J. Wales, and S. Nielsen, "Mortality rates in patients with anorexia nervosa and other eating disorders: A meta-analysis of 36 studies," Arch Gen Psychiatry, vol.68, no.7, pp.724-731, (2011)

[2] American Psychiatric Association, "Feeding and eating disorders," Diagnostic and statistical manual of mental disorders, Washington, DC: Author $5^{\text {th }}$ ed., pp.329-354, (2013)

[3] M. Nagl, C. Jacobi, M. Paul, K. Beesdo-Baum, M. Höfler, R. Lieb, and H.-U. Wittchen, "Prevalence, incidence, and natural course of anorexia and bulimia nervosa among adolescents and young adults," Eur Child Adolesc Psychiatry, vol.25, no.8, pp.903-918, (2016) 
[4] Canada Parliament House of Commons. "Eating disorders among girls and women in Canada / Hélène LeBlanc, Chair." Report of the Standing Committee on the Status of Women, Fourth report, 41st Parliament, 2nd session Ottawa, Ontario: House of Commons, (2014)

[5] C. Laird Birmingham and J. Treasure, "Medical management of eating disorders," Cambridge, New York: Cambridge University Press, (2010)

[6] M. I. Lapid, M. C. Prom, M. C. Burton, D. E. McAlpine, B. Sutor, and T. A. Rummans, "Eating disorders in the elderly," Int Psychogeriatr, vol.22, no.4, pp.523-536, (2010)

[7] K. A. Langlois, A. V. Samokhvalov, J. Rehm, S. T. Spence, and S. Connor Gorber, "Health state descriptions for Canadians: mental illness," Ottawa, ON: Statistics Canada, (2012)

[8] G. Raveneau, R. Feinstein, L. M. Rosen, and M. Fisher, "Attitudes and knowledge levels of nurses and residents caring for adolescents with an eating disorder," IJAMH, vol.26, no.1, pp.131-136, (2014)

[9] S. A. Trent, M. E. Moreira, C. B. Colwell, and P. S. Mehler, "ED management of patients with eating disorders," Am J Emerg Med., vol.31, no.5, pp.859-865, (2013)

[10] K. M. Frimenko, C. A. Murdoch-Kinch, and M. R. Inglehart, "Educating dental students about eating disorders: Perceptions and practice of interprofessional care," J Dent Educ., vol.81, no.11, pp.1327-1337, (2017)

[11] R. D. DeBate, L. A. Tedesco, and W. Kerschbaum, "Knowledge of oral and physical manifestations of anorexia and bulimia nervosa among dentists and dental hygienists," J Dent Educ, vol.69, no.3, pp.346-354, (2005)

[12] R. D. DeBate, S. B. Plichta, L. A. Tedesco, and W. Kerschbaum, "Integration of oral health care and mental health services: Dental hygienists' readiness and capacity for secondary prevention of eating disorders," J Behav Health Ser R., vol.33, no.1, pp.113-125, (2006)

[13] E. Kloczko, and M. N. Ikiugu, "The role of occupational therapy in the treatment of adolescents with eating disorders as perceived by mental health therapists," Occup Ther Ment Health, vol.22, no.1, pp.63-83, (2006)

[14] M. Clark, and S. Nayar, "Recovery from eating disorders: A role for occupational therapy," NZJOT, vol.59, no.1, pp.13-17, (2012)

[15] D. Boughtwood, and C. Halse, "Other than obedient: Girls' constructions of doctors and treatment regimens for anorexia nervosa," J Community Appl Soc, vol.20, no.2, pp.83-94, (2010)

[16] N. Davies, "The role of the nurse in eating disorder recovery," Independent Nurse., March, (2017)

[17] R. Bakker, B. van Meijel, L. Beukers, J. van Ommen, E. Meerwijk, and A. van Elburg, "Recovery of normal body weight in adolescents with anorexia nervosa: The nurses' perspective on effective interventions," J Child Adolesc Psychiatr Nurs, vol.24, no.1, pp.16-22, (2011)

[18] J. Carroll, "Eating disorders: A resource for practitioners providing community-based care," Provincial Eating Disorder Prevention and Recovery Program (PEDPRP) Women's Health Clinic, Winnipeg, MB, (2014)

[19] S. Hart, J. Russell, and S. Abraham, "Nutrition and dietetic practice in eating disorder management," J Hum Nutr Diet., vol.24, no.2, pp.144-153, (2011)

[20] A. M. Mittnacht, and C. M. Bulik, "Best nutrition counseling practices for the treatment of anorexia nervosa: A Delphi study,” Int J Eat Disorder, vol.48, no.1, pp.111-122, (2015)

[21] A. Cockfield, and U. Philpot, "Managing anorexia from a dietitian's perspective," Proc Nutr Soc, vol.68, no.3, pp.281-288, (2009)

[22] R. D. Rienecke, "Family-based treatment of eating disorders in adolescents: current insights," Adolesc Health Med Ther., 8, pp.69-79, (2017)

[23] [23] S. Bond, "Couple and family therapy: The evolution of the profession with social work at its core," OTSTCFQ 131, hiver, pp.128-138, (2009)

[24] E. Martinez, "Attitudes and perspectives of social work students on binge eating disorder treatments for adult females," California State University, San Bernardino, Electronic Theses, Projects, and Dissertations, (2017) 
[25] V. W. Gurney, and K. A. Halmi, "An eating disorder curriculum for primary care providers," Int J Eat Disorder, vol.30, no.2, pp.209-212, (2001)

[26] H. Green, O. Johnston, S. Cabrini, G. Fornai, and T. Kendrick, "General practitioner attitudes towards referral of eating-disordered patients: A vignette study based on the theory of planned behavior," Ment Health Fam Med, vol.5, no.4, pp.213-218, (2008)

[27] F. McNicholas, C. O'Connor, L. A. O'Hara, and N. McNamara, "Stigma and treatment of eating disorders in Ireland: Healthcare professionals' knowledge and attitudes,” Ir J Psychol Med, vol.33, no.1, pp.21-31, (2016)

[28] D. A. Banas, R. Redfern, S. Wanjiku, R. Lazebnik, and E. S. Rome, "Eating disorder training and attitudes among primary care residents," Clin Pediatr, vol.52, no.4, pp.355-361, (2013)

[29] A. Bannatyne, and P. Stapleton, "Educating medical students about anorexia nervosa: A potential method for reducing the volitional stigma associated with the disorder," Eat Disord., vol.23, pp.115-133, (2015)

[30] L. Girz, A. Lafrance Robinson, and C. Tessier, "Is the next generation of physicians adequately prepared to diagnose and treat eating disorders in children and adolescents?" Eat Disord., vol.22, no.5, pp.375-385, (2014)

[31] A. Lafrance Robinson, A. Boachie, and G. A. Lafrance, “'I want help!': Psychologists' and physicians' competence, barriers, and needs in the management of eating disorders in children and adolescents in Canada," Can Psychol, vol.54, no.3, pp.160-165, (2013)

[32] D. Linville, T. Brown, and M. O'Neil, "Medical providers' self-perceived knowledge and skills for working with eating disorders: A national survey," Eat Disord., vol.20, no.1, pp.1-13, (2012)

[33] W. Jones, S. Saeidi, and J. Morgan, "Knowledge and attitudes of psychiatrists towards eating disorders," Eur Eat Disord Rev, vol.21, pp.84-88, (2013)

[34] L. Currin, G. Waller, and U. Schmidt, "Primary care physicians' knowledge of and attitudes toward the eating disorders: Do they affect clinical actions?” Int J Eat Disord, vol.42, no.5, pp.453-458, (2009)

[35] T. Brockmeyer, H. Friederich, and U. Schmidt, "Advances in the treatment of anorexia nervosa: A review of established and emerging interventions," Psychol. Med., vol.48, no.8, pp.1228-1256, (2018)

[36] A. E. Kazdin, E. E. Fitzsimmons-Craft, and D. E. Wilfley, "Addressing critical gaps in the treatment of eating disorders," Int J Eat Disord., vol.50, no.3, 170-189, (2017)

[37] Canadian Psychology Association, "Psychology works," fact sheet: Eating Disorders, (2015)

[38] K. Weaver, "An exploration of the role of social support in health promotion for eating disorders," Virginia Henderson Global Repository, Sigma Theta Tau International Nursing Honor Society, (2013)

[39] M. Weber, and K. Davis, "Food for thought: Enabling and constraining factors for effective rural eating disorder service delivery," Aust J Rural Health, vol.20, pp.208-212, (2012)

[40] J. H. Rosenvinge, and G. Pettersen, "Do interprofessional educational programs on eating disorders provide proximal and distal benefits? Findings from a national cohort collected from 1998 to 2010," J Res Interprof Pract Educ, vol.6, no.1, (2016)

[41] World Health Organization, "World health report: Framework for action on interprofessional education and collaborative practice," Geneva, Switzerland: WHO, (2010)

[42] M. A. Craven, and R. Bland, "Better practices in collaborative mental health care: An analysis of the evidence base," Can J Psychiatry, vol.51(Suppl. 1), pp.1S-72S, (2006)

[43] O. Heath, D. English, J. Simms, P. Ward, A. Hollett, and A. Dominic, "Improving collaborative care in managing eating disorders: A pilot study," J Contin Educ Health Prof, vol.33, no.4, pp.235-243, (2013)

[44] H. Thompson-Brenner, D. A. Satir, D. L. Franko, and D. B. Herzog, "Clinician reactions to patients with eating disorders: A review of the literature," Psychiatr Serv., vol.63, no.1, pp.73-78, (2012)

[45] A. C. Ciao, K. Loth, and D. Neumark-Sztainer, "Preventing eating disorder pathology: Common and unique features of successful eating disorders prevention programs," Curr Psychiatry Rep., vol.16, no.7, pp.453, (2014);

[46] M. Strober, and C. Johnson, "The need for complex ideas in anorexia nervosa: Why biology, environment, and psyche all matter, why therapists make mistakes, and why clinical benchmarks are needed for managing weight correction,” Int J Eat Disord, vol.45, no.2, pp.155-178, (2012) 
[47] K. Weaver, "Loving her into well-being one day at a time: Narratives of caring for daughters with eating disorders," OJN. 2, pp.406-419, (2012)

[48] M. Levine and L. Smolak, "Toward a model of the developmental psychopathology of eating disorders: The example of early adolescence,” In: J.H. Crowter, S.E. Hobfol, M.A. Stephens, and D.L. Tennenbaum (eds), The Etiology of Bulimia Nervosa: The Individual and Familial Context, pp.59-80, Washington: Taylor and Francis, (2013)

[49] M. J. Zabala, P. Macdonald, and J. Treasure, "Appraisal of caregiving burden, expressed emotion and psychological distress in families of people with eating disorders: A systematic review," Eur Eat Disord Rev, vol.17, pp.338-349, (2009)

[50] E. Hughes, D. Le Grange, A. Court, M. Yeo, S. Campbell, M. Whitelaw, L. Atkins, and S. Sawyer, "Implementation of family-based treatment for adolescents with anorexia nervosa," J Pediatr Health Care, vol.28, no.4, pp.322-330, (2014)

[51] Yager, J., "Eating disorders: Overview of prevention and treatment," https://www.uptodate.com/contents/eating-disorders-overview-of-prevention-and-treatment, (2019)

[52] G. Dimitropoulos, A.F. Tran, P. Agarwal, B. Sheffield, and B. Woodside, "Challenges in making the transition between pediatric and adult eating disorder programs: A qualitative study from the perspective of service providers," Eat Disord, vol.21, pp.1-15, (2013)

[53] Statistics Canada, Census Profile, 2016, Parish, New Brunswick and New Brunswick Province, (2016)

[54] C. Esin, M. Fathi, and C. Squire, "Narrative analysis: the constructionist approach," In U. Flick, The SAGE handbook of qualitative data analysis, pp.203-216, London: SAGE, (2014)

[55] M. Tebogo, “Applicability of constructivist theory in qualitative educational research," Am Int J Contemp Res, vol.4, no.7, pp.51-59, (2014)

[56] M. Connelly, and D.J. Clandinin, "Stories of experience and narrative inquiry,” ER, vol.19, no.5, pp.2-14, (1990)

[57] S. Chase, "Narrative inquiry: Multiple lenses, approaches, voices," In N. Denzin, and Y. Lincoln, (Eds.), The Sage Handbook of Qualitative Research ( $3^{\text {rd }}$ ed.) Thousand Oaks, CA: Sage, (2005)

[58] C. Emden, "Conducting a narrative analysis, collegian," vol.5, no.3, pp.34-39, (1998)

[59] W. Austin, V. Bergum, and L. Goldberg, "Unable to answer the call of our patients: mental health nurses experience of moral distress,” Nurs. Inq., vol.10, no.3, pp.177-183, (2003)

[60] M. Weinberg and Moral distress, "A missing but relevant concept for ethics in social work," CSWR, vol.26, no.2, pp.139-151, (2009)

[61] W. Austin, M. Rankel, L. Kagan, V. Bergum, and G. Lemermeyer, "To stay or to go, to speak or to stay silent, to act or not to act: Moral distress as experienced by psychologists," Ethics \& Behavior, vol.15, no.3, pp.197212, (2005)

[62] W. Austin, "Moral distress and the contemporary plight of health professionals," HEC Forum, vol.24, pp.27$38,(\mathbf{2 0 1 2})$ 


\section{Authors}

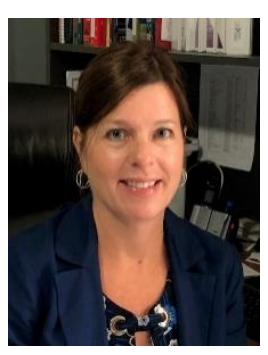

\section{Tanya Wilson}

She is a licensed social worker and Senior Health Consultant with the Government of New Brunswick, Canada.

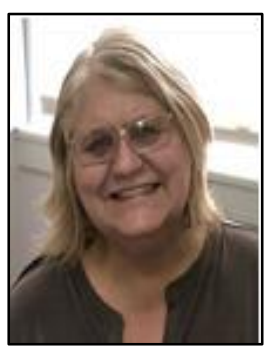

\section{Kathryn Weaver}

She is a Professor and Director of Graduate Studies Nursing at the University of New Brunswick, Canada. 
Seeing Beyond the Eating Disorder: The Complexities of Eating Disorder Care in New Brunswick, Canada

This page is empty by intention. 